\title{
REHABILITACIÓN Y RENOVACIÓN DEL CENTRO HISTÓRICO DE PINAR DEL RÍO (CUBA)
}

\author{
María de Jesús Laborí Capote \\ Centro de Estudios de Medio Ambiente y Recursos Naturales (CEMARNA), \\ Universidad de Pinar del Río «Hermanos Saíz Montes de Oca» (Cuba)
}

\section{RESUMEN}

La imagen urbana de la ciudad de Pinar del Río, cabecera de la provincia del mismo nombre y más occidental de Cuba, se ha deteriorado en los últimos años, la recuperación de su Centro Histórico, portador en si mismo de elementos que pueden resultar contradictorios desde la consideración de las vías que se proponen para la solución del problema que, por una parte, se plantea la recuperación de este Centro Histórico desde la perspectiva de su valor patrimonial; y por otro lado, dada la difícil situación económica, se decide explotar la vía del turismo para su puesta objetiva en valor funcional. Pero tal conjugación destaca el interés por rescatar la funcionalidad simbólica, sociocultural y económica que tuvo el núcleo genético de la ciudad, donde se concentraban y concentran hasta nuestros días, gracias a su gran centralidad, las principales funciones y exponentes arquitectónicos y urbanos de la misma.

Conjugamos los pensamientos posibilista y positivista para la recuperación histórica y patrimonial y a la vez contemporánea, de la arquitectura y el urbanismo, se acoge la entrada del turismo y los planes estratégicos, como vías recíprocas en función del rescate de la ciudad y de su desarrollo económico, ambos de primera necesidad, dada las posibilidades que ofrecen estos en el proceso de recuperación, como ha sido demostrado en el ejemplo exitoso de la recuperación de La Habana Vieja.

Palabras claves: Imagen urbana, recuperación, centro histórico, posibilismo, positivismo, turismo, plan estratégico.

\section{ABSTRACT}

The urban image of Pinar del Rio city, head of the province of the same name and most western province in Cuba, has deteriorated in recent years. The recovery of its historical center, carrier itself of elements which may be contradictory considering the means proposed for problems solution that, on one hand, there is the recovery of the Historical Center from the perspective of its heritage value, and on the other hand, given the difficult economic situation, it was decided to exploit the tourism for it's objective 
establishment in functional value. But such a combination highlights the interest in rescuing the symbolic functionality, social, cultural and economic conditions which the genetic core of the city had, where there where concentrated and still being concentrated to the present day, thanks to its high centrality, the main functions, architectural and urban exponents of the city core.

We combine the willing and positivist thoughts for the historic, hereditary and yet contemporary recovery of architecture and urbanism, the entry of tourism and strategic planning are implemented, both as reciprocal means dedicated to the rescue of the city and its economic development, considered basic necessities, given the possibilities offered by these in the recovery process, as it has been demonstrated in the successful example of the recovery of Old Havana.

Key words: Urban image, recovery, historical centre, the willing, positivist, tourism, strategic planning.

\section{Introducción}

La ciudad de Pinar del Río y su centro histórico, contienen un cúmulo de valores patrimoniales y simbólicos cuya recuperación merece la pena en sí misma, por ser expresión de la cultura y las tradiciones locales. Participamos pues del punto de vista historicista. No obstante, en atención a las peculiaridades del sistema cubano y a las especiales circunstancias económicas actuales del país, que a partir del año 1990 se decide apostar por la actividad turística como un medio importante de restablecer su economía, plantamos una propuesta científica que pretendidamente adopta el planeamiento estratégico como divisa, pero sin descuidar el pensamiento posibilista que nos identifica ante todo lo rescatable de la arquitectura y el urbanismo de la ciudad y principalmente de su centro histórico.

La Provincia Pinar del Río limita al Norte: Golfo de México; por el Oeste: Estrecho de Yucatán; el Mar Caribe por el Sur, y por el Este la provincia de La Habana. Es la provincia más occidental de Cuba.

La Ciudad de Pinar del Río, principal centro urbano de la provincia pinareña, y su capital, a una distancia de $148 \mathrm{~km}$ de la Ciudad de La Habana, capital del país, con una población de alrededor de 140.000 habitantes y un área total de 3.240 ha.

Los valores patrimoniales existentes en el centro histórico de la ciudad de Pinar del Río, representan lo más autóctono de la cultura pinareña y sus raíces, por lo que su recuperación y aprovechamiento racional es un aspecto indispensable para el futuro de la ciudad y de sus pobladores, el rescate del ambiente cívico, las costumbres, las tradiciones, los valores, tienen que marchar de la mano de la recuperación física, para poder lograr una propuesta de cualificación de la imagen urbana desde la rehabilitación y renovación de la ciudad y su centro histórico.

En los países desarrollados, desde la crisis internacional padecida a mediados de los años 1970 , se asiste a nuevas fórmulas de planeamiento y ordenación del territorio que son antecedidas por planes estratégicos y formulaciones ágiles que permitan adaptarse a las circunstancias, lo que en los momentos actuales cobra actualidad ante la nueva crisis económica que se avecina. Esto es, se definen unos planteamientos estructurales y unos objetivos precisos, pero los procedimientos para alcanzarlos son coyunturales y flexibles. Se pretende evitar la promulgación de objetivos que el tiempo convierta en inalcanzables y, por consiguiente, se procura introducir herramientas de trabajo más pragmáticas y ajustadas a la cambiante realidad. También en Cuba, la crisis ha hecho posible mirar el patrimonio histórico con nuevos ojos. 
FIgURA 1. Ubicación geográfica en la Isla de Cuba, su Provincia más occidental, Pinar del Río, su capital: la Ciudad de Pinar del Río y su centro histórico.

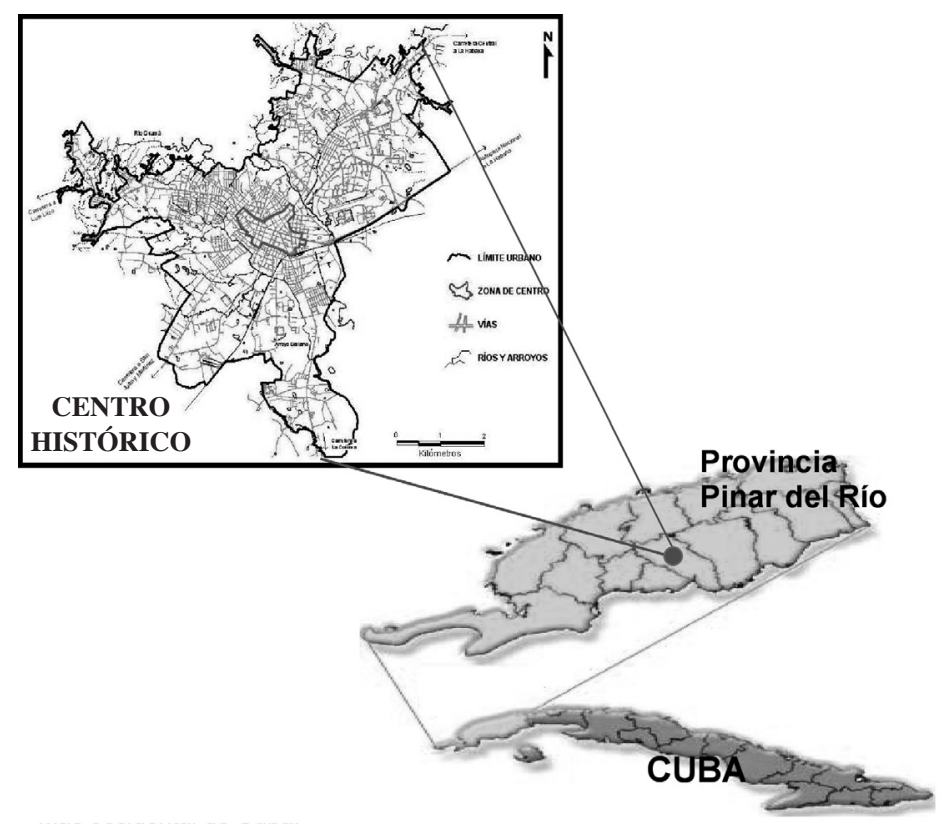

Procedimientos como los descritos han sido utilizados con éxito en algunas ciudades europeas, entre las que sobresale el ejemplo de Barcelona y la rápida y espectacular recuperación de su centro histórico a partir de un plan estratégico. En Cuba destaca el caso no menos llamativo de La Habana Vieja, del que su Plan Maestro es fruto también de un planeamiento estratégico que fue esbozado en 1994. En ambos casos se trata de procesos exitosos de recuperación funcional, económica, simbólica y social de sus centros históricos, en los que su puesta en valor para el uso turístico y terciario en general ha sido motor

Figura 2 y 3. Calle José Martí eje del centro histórico y corazón de la ciudad pinareña.
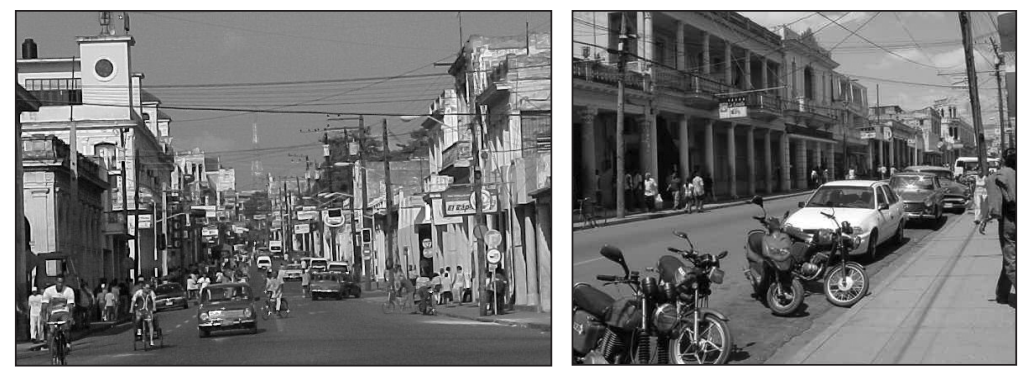

FUENTE: colección de la autora. 
Figuras 4 y 5. Dos imágenes de la Habana Vieja, donde se aprecia el proceso de intervención y recuperación con una integración histórico-contemporáneo.
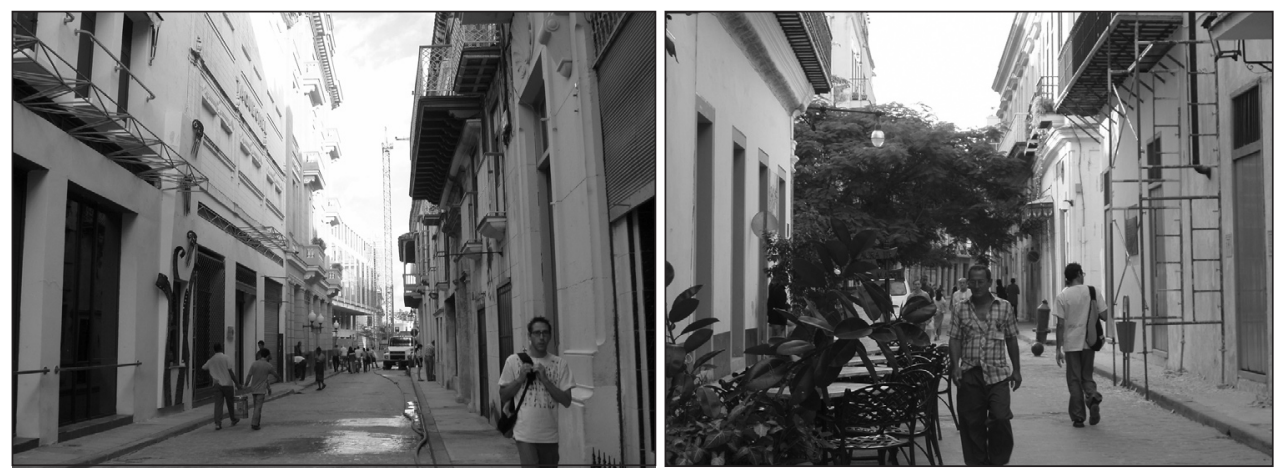

FUENTE: colección de la autora.

destacado de las actuaciones y, en el caso cubano, casi en el único agente económico que garantiza la ejecución del proyecto y su viabilidad futura.

Tenemos bien presente que tal proceso puede desembocar en una monoespecialización funcional del área histórica en actividades terciarias vinculadas al turismo. Se trataría entonces de un paso más conforme con las premisas del pensamiento positivista: el diseño de un área concreta - el centro histórico - para acoger una función específica - la turística- . En ese sentido, un mal plan puede llevar a una concepción utilitarista del patrimonio y a la «re-creación» de un falso escenario historicista que, con criterios museísticos, acabase convirtiendo el centro histórico de Pinar del Río en un parque temático al servicio del turismo, como es el caso en Cuba de Trinidad.

Frente a esa amenaza, planteamos una propuesta de recuperación integral que, a la vez que atiende al patrimonio y a la forma física en su conjunto, presta especial atención también al tejido social y al patrimonio intangible. Como se decía antes, la crisis cubana de los años 1990 - el «periodo especial»- ha provocado una nueva mirada hacia la ciudad existente, hacia la ciudad histórica, que conjuga el interés historicista por la recuperación de un patrimonio de indudable valor, con el interés más pragmático de explorar nuevas vías de desarrollo económico y social gracias a su puesta en valor de cara al turismo.

El nuevo punto de vista reúne, además, otros componentes como son el de la mayor sostenibilidad propugnada por el urbanismo de la austeridad, la defensa de la ciudad compacta frente a la ciudad difusa y fragmentada, tanto por cuestiones económicas (infraestructuras y equipo para desplazamientos) como por los recursos consumidos (suelo, paisaje y tiempo entre los principales, además de energía y materiales de construcción). La revalorización de la ciudad compacta y del modelo historicista supone, además, el redescubrimiento de un escenario físico que potencia el encuentro, la relación, los usos comunitarios y las prácticas socializantes, más conformes con el ideario de la Revolución.

Las estrategias elaboradas en 1994 para el centro histórico de la Ciudad de La Habana, en su conjunto recogen el cambio del paradigma del modelo urbano: se abandona la ciudad zonificada positivista y se recupera la ciudad compacta historicista y sus formas de vida. El nuevo enfoque contempla, entre sus objetivos, la recuperación del centro histórico y de la ciudad compacta frente a los problemas de medio ambiente inhabitable de las grandes ciudades contemporáneas; se procura la escala humana frente al gigantismo y la pérdida de control; busca acabar con los procesos de pérdida de vida colectiva; quiere 
Figuras 6 y 7. Imágenes de una calle de la ciudad de Trinidad y del parque Central, donde se aprecia su restauración totalmente historicista.
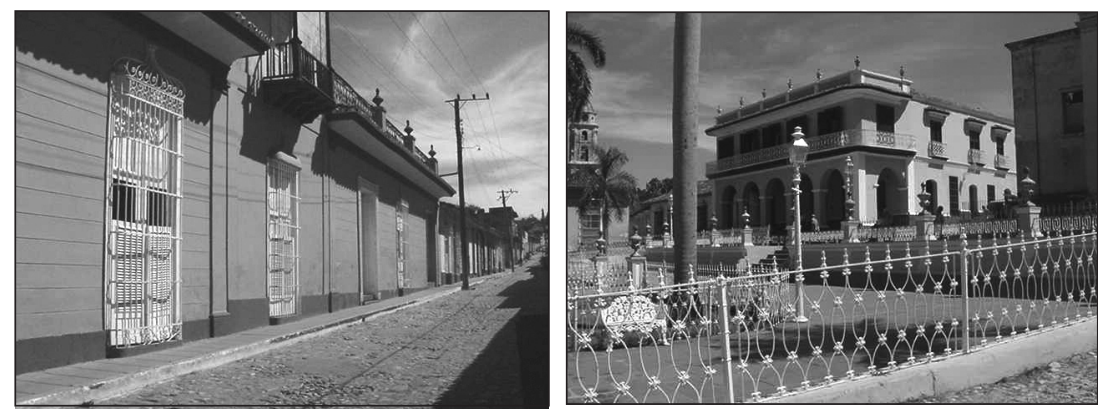

FUENTE: colección de la autora.

poner freno a la fragmentación centrífuga de la forma física y, con ella, de la forma social (limitar la ciudad difusa); intenta poner coto a la pérdida y destrucción de lugares valiosos; propone la recuperación del sentido de lugar - el topos - frente a la ciudad banal de los «no lugares»; se orienta hacia la búsqueda de modos de vida más sociales con el objeto de frenar la conversión de los centros históricos en almacenes de personas sin recursos. En definitiva, en tiempos de crisis se promueve el urbanismo de la austeridad frente al urbanismo del derroche.

Conforme con esos criterios, la propuesta que realizamos para la ciudad y el centro histórico de Pinar del Río se fundamenta en los siguientes principios:

- se reivindica el uso público de los suelos para recrear espacios de relación: plazas y nuevas instalaciones gastronómicas, comerciales y de servicios;

- se respalda los cambios de usos de los locales con funciones no compatibles con la actividad de centro de ciudad y de ciudad;

- se defiende la permanencia de las clases populares (lucha contra la segregación) y la introducción de nuevos habitantes, mediante la mejora de la habitabilidad de la ciudad y su centro histórico (exige la incorporación de servicios y equipamientos, de diferentes niveles de uso);

- se defiende la arquitectura histórica (no historicista para evitar pastiches descontextualizados) y se favorece la rehabilitación, para no favorecer la expulsión de las clases populares (frente a la renovación urbana y social);

- se rechaza la zonificación racionalista, la segregación de usos y la expulsión especulativa de actividades hacia la periferia: se aboga por la mezcla, la saturación del suelo conforme con la tradición histórica, se desea frenar la terciarización del centro histórico y diversificar todo lo posible los usos de la ciudad;

- se rescatan las tradiciones que por problemas de carácter más subjetivos que objetivos se han perdido y crear valores de satisfacción social que reafirmen el orgullo e identidad pinareña como elemento inseparable de la cubanía;

- se establece la prioridad de ser realistas y equilibrados a la hora del plan: planear conforme a los recursos públicos reales que promulgue un programa objetivo, creativo y de posibilidades financieras, evitar megalomanías incumplibles y posibilitar ajustar el plan de modo flexible y abierto, ajustando los objetivos a las coyunturas; 


\section{Restricciones para el impulso de las potencialidades de la ciudad de Pinar del Río para el desarrollo del turismo}

Existen grandes restricciones que es necesario vencer para el desarrollo de un turismo estable y de estancia en Pinar del Río, todas completamente superables, no en igual período de tiempo, ni de esfuerzo, sino con un consecuente programa de actuación por etapas, con la participación de todos y dentro de un «Plan Especial de Recuperación». Entre lo más significativo que limita el impulso del turismo de ciudad se puede citar:

1. Falta del parque de recreación urbano de la ciudad planificado y proyectado con el nombre de «Parque Guamá», que podría tener una implementación por etapas. No se ha iniciado.

2. El Jardín Botánico, con excelentes potencialidades para su explotación, por la cantidad de especies autóctonas con que cuenta la provincia, y el asegurado interés que despertaría, así como los beneficios que aportaría. Se implementa muy lentamente y no cuenta con los recursos necesarios para su adecuada materialización.

3. Las áreas previstas para el parque Zoológico no se están preservando, con peligro de perderse por ocupaciones inadecuadas y no previstas.

4. La pérdida de tradiciones socio-culturales que darían animación y representarían un fuerte atractivo para la ciudad por ejemplo las verbenas pinareñas, las celebraciones de jornadas y fechas significativas, las retretas, bailes de disfraces, los sábados pinareños, entre otras.

5. Las capacidades de alojamiento hotelero son bajas y no tienen el confort y la calidad necesaria para su eficaz comercialización. Hoteles de un valioso valor arquitectónico, locacional e histórico, se encuentran en crítico o regular estado y no cuentan con opciones para una inversión a corto plazo.

6. La falta de estudio y ofertas del turismo cultural vinculado a la naturaleza, desaprovechando las potencialidades de la ciudad, sus hospitalarios pobladores y su entorno, sin existir una clara comprensión de las posibilidades de este producto en Pinar del Río.

7. Carencia de propuestas de recorridos peatonales por la ciudad, aprovechando la presencia de industrias manufactureras, de producciones autóctonas como el licor «Guayabita del Pinar», la elaboración del tabaco en diferentes puntos, no solo en la única fábrica existente, las galerías de pintura y arte con la obra de los prestigiosos artistas pinareños y otros valores socioculturales propios.

8. Pérdida de la tradición culinaria, los ahumados, el tamal en cazuela, el arroz con pollo a la chorrera, el guiso criollo, los dulces en almíbar, etc. Esto unido a la falta de calidad en la oferta gastronómica de los restaurantes existentes, limita esta potencial oferta.

9. El deterioro de las instalaciones que pueden ser atractivas para fines turísticos, específicamente aquellas en las que se brindan servicios en moneda nacional, debido a la falta de una política de mantenimiento y conservación. Esto ha jugado un papel importante en la poca estancia del turista, y su necesario vínculo con los pobladores del lugar.

10. Subutilización de las instalaciones deportivas, campos de tenis, terrenos de carreras de autos y motos, estadio de pelota. Estos deportes de gran tradición y fortaleza en Pinar del Río con una buena explotación darían un gran encanto al territorio vueltabajero.

11. La recogida de los desechos sólidos y el transporte de personas con carros de tracción animal sin crear las condiciones adecuadas, han deteriorado el medio ambiente urbano. Constituye una problemática que tiene solución a corto plazo, a partir de crear las condiciones apropiadas. 
12. El deterioro del fondo edificado con fines comerciales y gastronómicos, lo que se visualiza más intensamente en los que brindan servicio en moneda nacional, debido a la falta de una política de mantenimiento y conservación. Esto ha jugado un papel importante en la poca estancia del turista.

13. Limitada promoción por parte de la provincia de las cadenas turísticas nacionales así como con entidades nacionales e internacionales, para impulsar un turismo de estancia en Pinar del Río y no continuar tratando el producto de este rico territorio solo como una opcional más.

14. No se ofrecen servicios variados al turismo entre los cuales pueden mencionarse el comercio, la gastronomía, las tradiciones locales y la cultura en todas sus manifestaciones. El recorrido actual, que es de paso, está limitado a las fábricas de Tabaco y Guayabita del Pinar, a la Casa del Habano y al Museo de Ciencias Naturales, entre otros, no explotando los potenciales que existen en la ciudad principalmente de orden cultural teniendo en cuenta el patrimonio y el reconocido potencial artístico de la provincia.

15. Falta de programas y ofertas a los visitantes que vinculen e incluyan la ciudad con el turismo de naturaleza, lo que ampliaría la estancia de los turistas en Pinar del Río.

\section{El modelo urbano de Pinar del Río y su actividad turística}

La ciudad de Pinar del Río adquiere el carácter de ciudad en el año 1867, es una ciudad monocéntrica, con una estructura radial, alrededor de un eje lineal, la conforman dos grandes zonas, divididas por el río Guamá, la zona histórica-tradicional y la zona de nuevo desarrollo. Hasta el triunfo de la Revolución se mantuvo entre las ciudades más atrasadas del país.

El desarrollo de la ciudad de Pinar del Río desde el año 1959 hasta 1990, fue muy intenso y apreciable, la construcción masiva de viviendas y edificaciones sociales: educacionales, de salud, de deporte y servicios, sobre todo en la zona noreste de la ciudad.

La pasada década de los años 90, denominada «periodo especial», se caracterizó por un notable estancamiento, derivado de que comienza a sentirse en el país el impacto de la caída del campo socialista con el consiguiente agravamiento de la situación económica interna, y en los últimos años, también se ha visto afectado por la acción de cuatro fuertes huracanes. Esto ha incidido en un apreciable deterioro de la imagen urbana de la ciudad y su medio ambiente, además, también producto de la falta de mantenimiento, todos los recursos fueron destinados, en las tres primeras décadas, a las nuevas construcciones, lo que ha llevado a una etapa actual a una urgente etapa de recuperación.

Figura 8. Calle José Martí vista desde el parque de la Independencia.

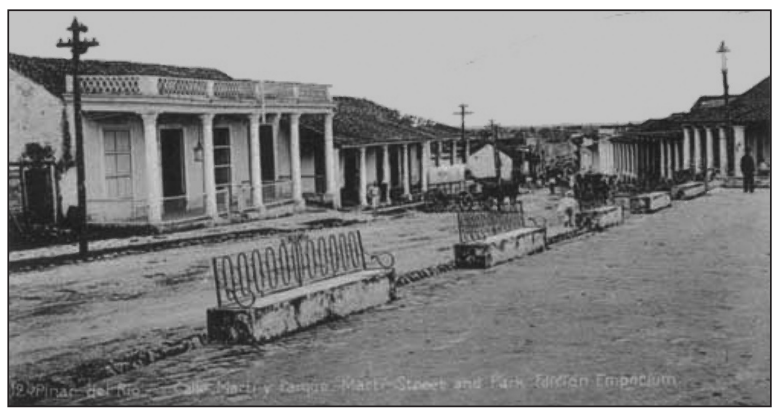

FUENTE: Sitio Web, Estampas de Vueltabajo de Gerardo Ortega. 
FIGURA 9. Nuevo Desarrollo de Viviendas al noreste de la ciudad tradicional.

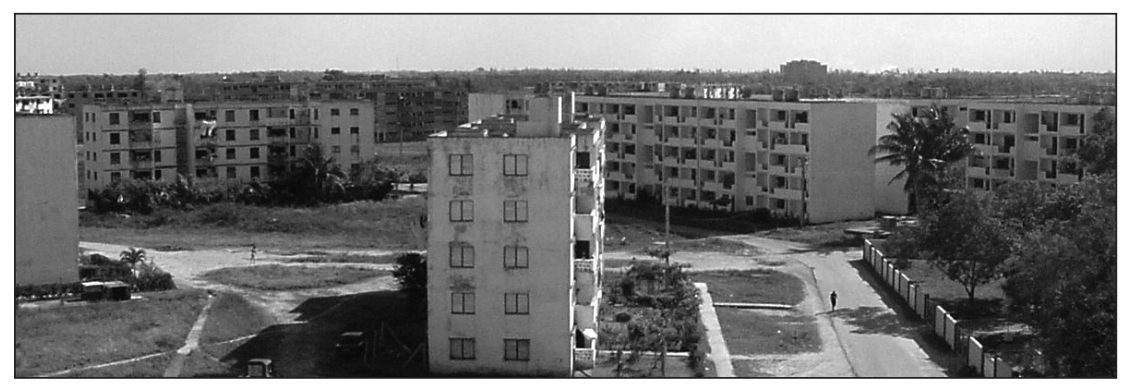

FUENTE: colección de la autora.

No aparece ninguna manifestación de turismo a lo largo de todo el siglo XIX. En la primera mitad del siglo XX, van apareciendo las primeras edificaciones hoteleras en la ciudad de Pinar del Río. Hoteles como el Gustavo (1904), (hoy Hotel Comercio en restauración), el Globo (se quema en 1906, restaurado en el 1910), El Cándamo (1901, ocupado por El Globo del 1906 al 1910, El Baturro 1920 y finalmente Hotel Presidente 1950, actualmente no funciona como hotel), y el Ricardo (1929), (hoy Vueltabajo recién restaurado), todos ellos constituyeron enclaves representativos de la hotelería pinareña. Los visitantes en general, eran básicamente comerciantes en busca de negocios y no turistas.

El turismo no tuvo ninguna significación en la ciudad de Pinar del Río en la primera mitad del siglo pasado. Para el turismo local se desarrolla la playa Las Canas a $22 \mathrm{Km}$. (13,67 millas) de la ciudad. Esta playa, se populariza en la década del 1950 y en temporadas veraniegas era la opción recreativa de los pobladores de la ciudad.

El turismo que accede hoy a la ciudad de Pinar del Río, es fundamentalmente de paso, a pesar de que la ciudad se caracteriza por una arquitectura con un sello muy distintivo por la presencia de portales, columnas, tejas criollas y elementos ornamentales con un aceptable grado de conservación, aspectos que resultan muy atractivos para los que la visitan y para el futuro desarrollo de un turismo cultural y de ciudad, así como las indiscutibles bellezas naturales de su entorno que hacen de la provincia un polo de alto potencial para el turismo de naturaleza.

Los visitantes han permanecido como promedio en los últimos años: en 1995: 2,3 días, en el 1996: 2,1 días, desde 1997 hasta el 2001: 1.8 días, en el 2002 subió a 1,9 días, en el 2003: baja a 1,8 días y en el 2004: 1,75 días. Lo que demuestra que la tendencia de la estancia de los turistas en Pinar del Río, a partir de 1996, ha sido disminuir.

El alojamiento para el turismo tiene como únicas ofertas en estos momentos, el hotel Pinar del Río, con una capacidad de 149 habitaciones y el hotel Vueltabajo, recién restaurado, con 40 habitaciones, ambos de la cadena Islazul, y en la base de campismo Aguas Claras, de la cadena Cubamar, con 50 habitaciones - en las afueras de la ciudad - , existen también, en casas particulares 70 habitaciones que ofertan servicios a los turistas. Dentro del centro histórico de la ciudad se localizan además, el Hotel Comercio, considerada su instalación hotelera más emblemática, no tiene un inversionista que acometa la inversión para su rescate, luego de varios intentos.

La ciudad carece de una red adecuada que ofrezca servicios variados al turismo entre los cuales pueden mencionarse la gastronomía, las tradiciones locales y la cultura en todas sus manifestaciones, entre otros, que inciden en el problema planteado. 
En este sentido, el centro histórico de Pinar del Río constituye el principal recurso, susceptible de convertirse en factor de atracción del turismo y de brindársele un adecuado tratamiento, mediante la recuperación patrimonial y medioambietal, en un contexto urbano aquejado hoy por graves patologías.

Por ello se propone un método de análisis, diagnóstico y propositivo sobre el centro histórico de la ciudad de Pinar del Río.

La red vial es adecuada, aunque existen problemas de drenaje pluvial en algunos puntos de la ciudad. El abastecimiento de agua es insuficiente, existiendo a corta distancia de 15 $\mathrm{Km}$. fuentes de abasto de agua de gran calidad y buen potencial, con el inconveniente de que la red de distribución se encuentra en mal estado, produciéndose grandes pérdidas, la red de alcantarillado está incompleta, además se requieren de mejoras en la recogida de desechos sólidos, las comunicaciones y en el sistema de transporte público.

Consideramos que para el desarrollo de nuestro trabajo, se parte de una ciudad con potencialidades reales como destino turístico, y un encanto acogedor, rodeada de hermosos y diversos paisajes así como recursos naturales que le han conferido entre otros el nombre de Catedral Natural de Cuba.

Con relación al estado del tema debe señalarse que han existido en Cuba diversas soluciones de carácter empírico, pero carentes de un fundamento científico, dirigidas al perfeccionamiento de la actividad turística aunque fundamentalmente dirigida a destinos de Sol y Playa, el destino ciudad tiene ejemplos muy concretos con La Habana Vieja y Trinidad, ambas Patrimonio Cultural de la Humanidad. El turismo de ciudad y su relación con la Naturaleza, en ciudades con patrimonio pero sin grandes atributos, ha sido escasamente tratado. De ello se deriva la pertinencia y actualidad del tema planteado.

\section{El problema que debemos enfrentar y resolver}

De lo planteado en los párrafos anteriores se puede derivar la necesidad en función del desarrollo económico local, de fomentar el impulso del turismo, dado que, el centro histórico de Pinar del Río atesora valores patrimoniales objetivos, susceptibles de recuperación para el acervo local, para redotarse de nuevas funciones de centralidad y para la mejora de las condiciones de habitabilidad. Se entiende que su puesta en valor para el turismo constituye una herramienta estratégica que permitirá las actuaciones inmediatas y la sostenibilidad a largo plazo de las propuestas de recuperación. En ese sentido, a día de hoy, el turismo que accede a la ciudad de Pinar del Río es fundamentalmente de paso, ya que el centro

Figura 10. Centro Histórico de la ciudad de Pinar del Río.

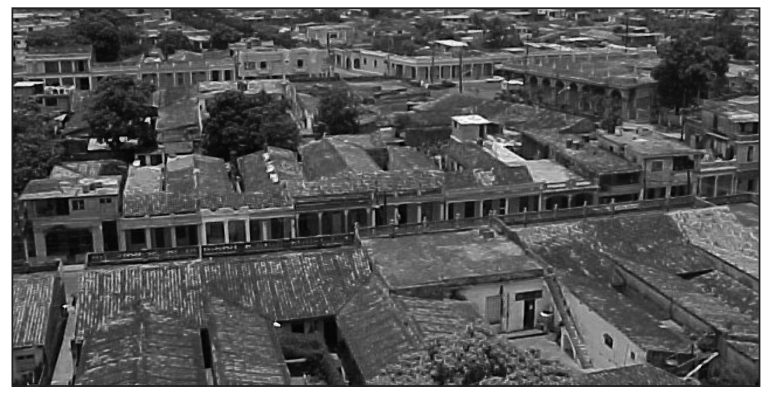

FUENTE: colección de la autora. 
histórico de la ciudad - y aún toda la ciudad - carecen de equipamientos específicos para atraerlo. Aprovechando el flujo existente de turismo de naturaleza, se propone contribuir a la modificación de esta situación, con vistas a lograr un turismo de estancia que, además de a la recuperación del patrimonio arquitectónico y urbano, ayude al desarrollo económico de la ciudad y de la provincia de forma más equilibrada y sostenible.

La ejecución de un programa integral para la rehabilitación y renovación del centro histórico de la ciudad de Pinar del Río que conduzca al rescate de los valores estéticos, arquitectónicos y socioculturales, la reanimación de los servicios, el perfeccionamiento de la infraestructura urbana, el mejoramiento de la imagen urbana y el medio ambiente de la ciudad, privilegiando el desarrollo de los espacios verdes, contribuirá a incrementar la estancia de los turistas en Pinar del Río y a un desarrollo económico más equilibrado.

En estos momentos la promoción del Polo Turístico Ciudad Pinar del Río se ha apoyado sustentadamente sólo en ese reconocido privilegio de una naturaleza prodiga que la rodea y envuelve, pero es indudable que no ha tenido en cuenta su inapreciable legado urbanístico, arquitectónico y cultural. El patrimonio cultural se asumió, fundamentalmente, en sus aristas contemplativas, sin que se aprovechara a plenitud el valor de esos ambientes, las tradiciones y su patrimonio sosegado, como valiosos e incalculado atractivo para el turismo.

Los turistas que arriban cada año a Pinar del Río, van con una idea muy pobre de su cultura local y una vez allí, disponen de escasas posibilidades de un acercamiento a la herencia patrimonial que ha quedado, a los hitos históricos, a la tradición cultural. Las Casas Matrices de las diferentes cadenas turísticas en Cuba, apenas promueven opciones para prolongar la estancia de los visitantes en esa provincia, sólo se enseñan como pinceladas las manufactureras fábricas de Tabacos y Guayabita del Pinar. No se ha proyectado un producto integral que enlace, turismo cultural, de ciudad y de naturaleza, considerando que existen sobrados valores y recursos para su explotación adecuada y consecuente.

Figura 11. Vista de la calle José Martí eje principal del centro histórico de Pinar del Río, desde el parque de la Independencia.

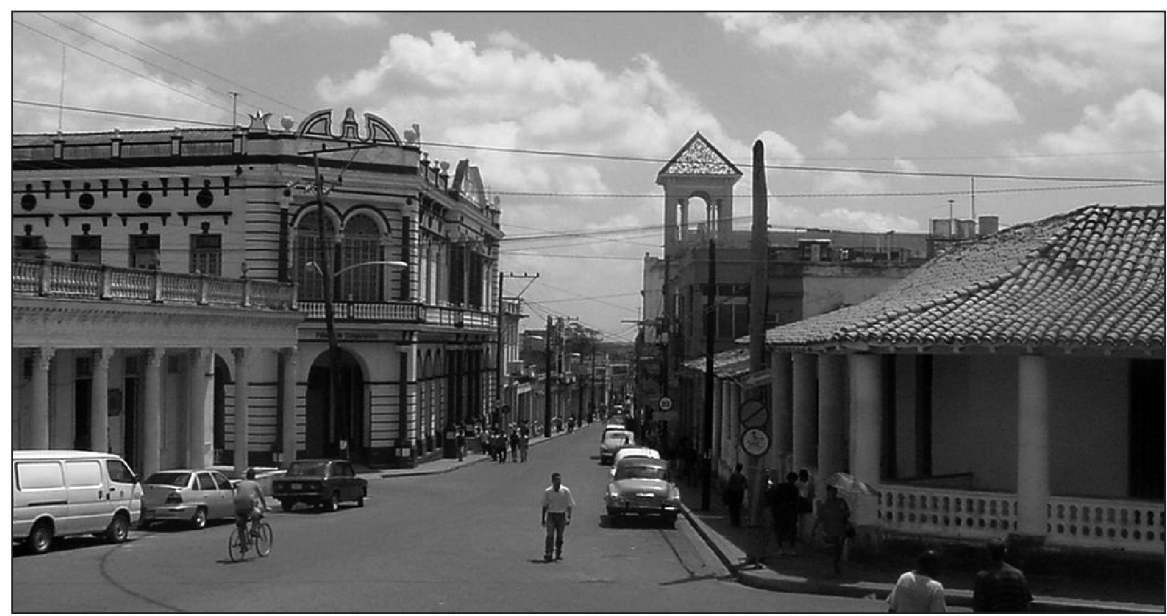

FUENTE: Colección de la autora. 
FIgURA 12. Arquitectura tradicional pinareña, calle José Martí, en su tramo menos comercial.

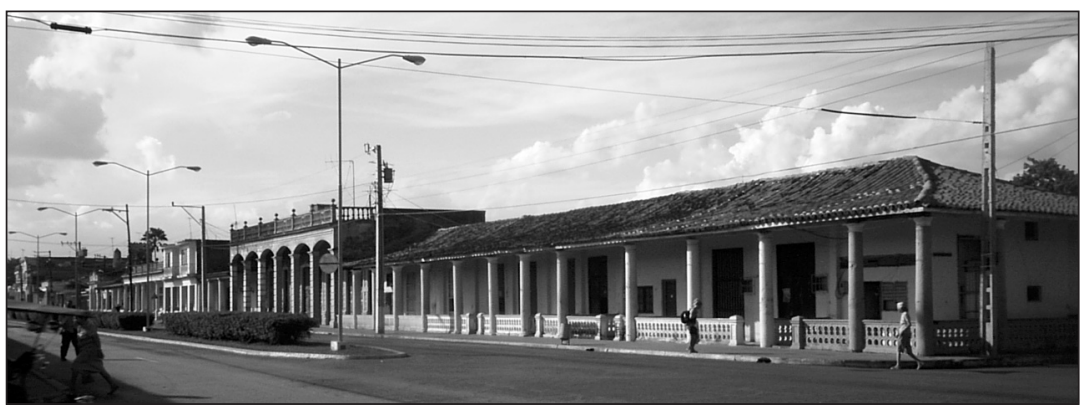

FUENTE: Colección de la autora.

Por esto resulta de gran importancia que en los próximos años la industria del turismo en el país y por ende en esta provincia, incluyan estrategias que potencien las modalidades de turismo cultural, de ciudad y de naturaleza. La ciudad de Pinar del Río puede ofertar una cultura popular y auténtica porque es una ciudad con valioso encanto pueblerino y con un entorno de unos recursos naturales excepcionales. Esa es la riqueza que hay que preservar, acondicionar y promover. Así, luego de siglos de tabaco, café y esclavitud el Polo Turístico Ciudad Pinar del Río será un destino más agradable, transformando la ruta del esclavo en los senderos del turismo cultural y en un centro histórico rehabilitado y reanimado, unido claro está a esa riqueza natural y poco antropisada que rodea a la ciudad capital de Vueltabajo.

Al aproximarnos; además, a la práctica del turismo, a idea de la cultura y del desarrollo cultural, igualmente obtenemos la posibilidad de abrir nuestra región a un coexistir cultural con todos los países del mundo que puedan venir para prácticas turísticas sanas y para ayudar incluso a enriquecer nuestra cultura o para enriquecerse ellos mismos con la riqueza cultural de Pinar del Río.

Figura 13. Palacio Guasch, actualmente el museo de Ciencias Naturales Tranquilino Sandalio de Noda, edificio emblemático de la ciudad. Colección de la autora.

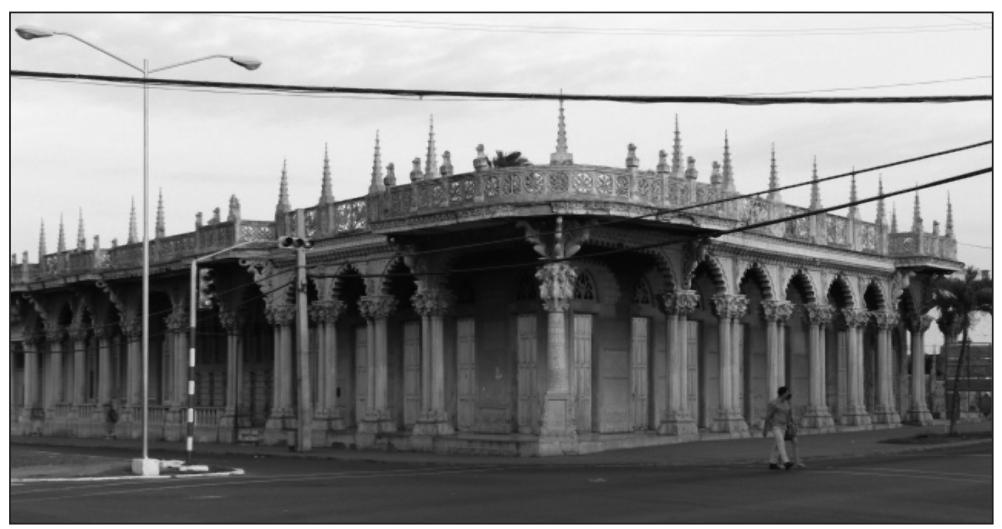




\section{Las propuestas para enfrentar el fomento del turismo en función del desarrollo local, en Pinar del Río}

Para llevar a efecto la propuesta del Plan de Rehabilitación y Renovación del Centro Histórico de Pinar del Río, se establecen un conjunto de lineamientos que deben cumplirse

1. Crear una oficina, vinculada directamente al Gobierno del Municipio, con capacidad técnica, de acción y gestión, autoridad legal y fuero, dirigida por una figura líder con prestigio y capacidad, para llevar a cabo la recuperación y rehabilitación integral del centro histórico de la ciudad de Pinar del Río.

2. Para la mejora de la imagen urbana, elaborar un estudio de las fachadas a escala peatonal en toda el área del centro histórico, que incluya hasta la solución de colores. Dicho estudio será elemento regulador de todas las acciones de intervención, modificación o cambio de uso que se vayan a ejecutar, recogidas en un documento oficial, que pudiera nombrarse Regulaciones Especiales del Centro Histórico, aprobado en las instancias competentes y con carácter legal.

3. Establecer los mecanismos necesarios para que las ganancias, impuestos y donaciones que se generen, sean invertidos en una primera etapa netamente, en las acciones de rescate y reanimación del centro histórico de Pinar del Río, y en etapas posteriores un porciento previamente pactados de los mismos.

4. Recuperar la imagen tradicional del centro histórico de la ciudad de Pinar del Río, posibilitando el mantenimiento integral del ambiente urbano, así como las funciones terciarias originarias, las tradiciones, el completamiento del mobiliario urbano y la restauración progresiva de todas las edificaciones, en primer orden las seleccionadas en el Catálogo de Bienes a Proteger, mediante las acciones señaladas a acometer.

5. Rescatar el patrimonio inmueble por, con y para los pobladores de la ciudad, desde la ejecución de un programa integral que esté conformado por un criterio sociocultural y con respeto a la historia, potenciando los espacios con vocación para el desarrollo de las diferentes actividades y la reanimación del ambiente cívico de la ciudad.

6. Rescatar toda la red de instalaciones hoteleras originales, fomentar las habitaciones para el hospedaje en casas particulares, así como la red gastronómica con sus tradiciones culinarias pinareñas.

7. Mantener, incrementar y fomentar el verde urbano, en parques, plazas, paseos, espacios ajardinados y en todo el entorno urbano, cualificando su percepción y el medio ambiente del centro histórico y la ciudad.

8. Continuar incentivando el programa de cambios de uso con el traslado de las instalaciones con funciones incompatibles con el centro histórico de la ciudad, rescatando los usos originales para la revitalización y reanimación del mismo.

9. Conseguir que la actividad comercial ambulante, tanto estatal como privada, se integre de forma coherente y con calidad expresiva, a la imagen urbana del centro histórico de la ciudad.

10. Promover el uso de los edificios de valor arquitectónico y patrimonial, seleccionados como bienes a proteger, con funciones de interés social, incluyendo las de comercialización y promoción de los recursos turísticos de la ciudad y de todo el territorio de la provincia.

11. Aprovechar las distancias peatonales del centro histórico y la potencialidad que representa la apreciación de la imagen urbana a nivel peatonal, para potenciar los senderos y recorridos urbanos, en función del conocimiento de la ciudad, sus atractivos arquitectónicos, urbanos, socioculturales e históricos. 
Figura 14. Fichas 26 y 26a del Catálogo de Bienes, Espacios y Calles a Proteger del Centro Histórico de Pinar del Río.
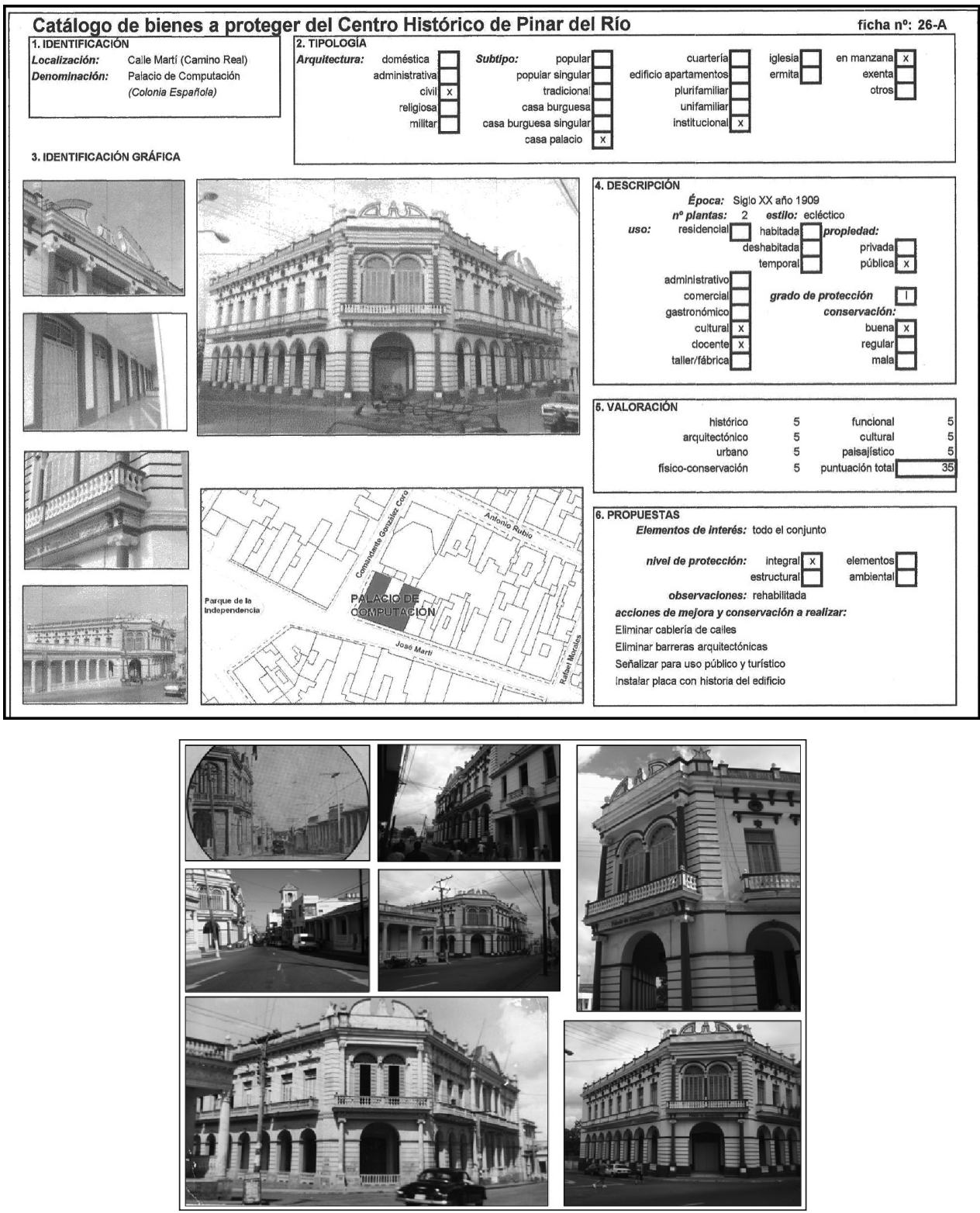

Elaboración propia.

12. Implementar la propuesta de «Plan integral para la recuperación: rehabilitación y renovación del centro histórico de la ciudad de Pinar del Río», por etapas y en la medida de las posibilidades. 
Figura 15. Pág.1 del Catálogo de Espacios a Proteger del Centro Histórico de Pinar del Río.

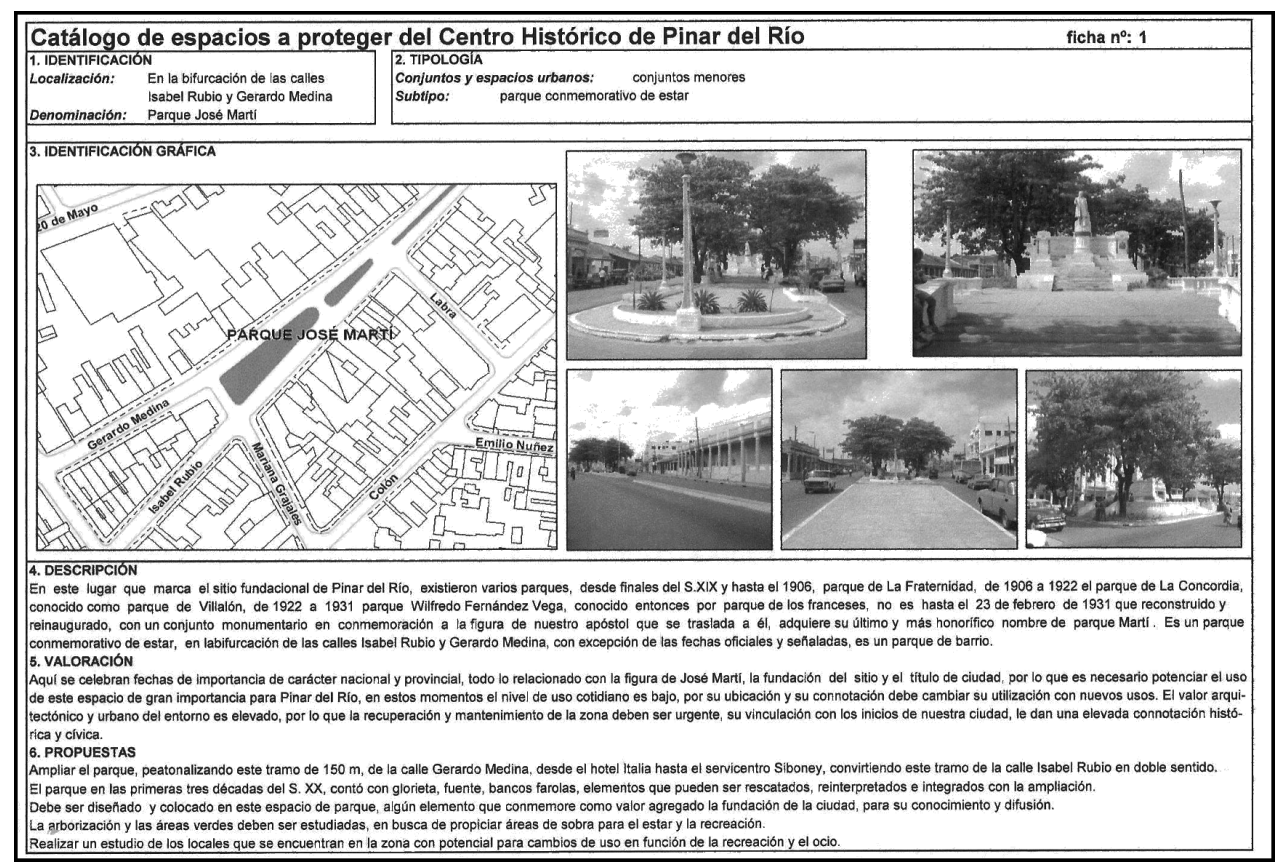

Elaboración propia.

\section{Conclusiones}

En consecuencia el nuevo aporte al desarrollo de la ciudad de Pinar del Río, que incluye: nuevos empleos, el rescate de tradiciones, el rescate de funciones, el rescate de valores; reside en la determinación de los fundamentos de una propuesta de «Plan integral para la recuperación: rehabilitación y renovación del centro histórico de la ciudad de Pinar del Río», en la que se funden lo histórico, lo arquitectónico, lo sociocultural y lo ambiental a partir de una reinterpretación de la historia de la ciudad que permite establecer los nexos con el desarrollo arquitectónico, sociocultural y turístico del territorio, basado en un pensamiento que establece un equilibrio entre las dos tendencias actuales: el posibilismo y el positivismo.

Consideramos que la creación de una oficina, vinculada directamente al Gobierno del Municipio, con capacidad técnica, de acción y gestión, autoridad legal y fuero, dirigida por una figura líder con prestigio y capacidad, para llevar a cabo el plan de recuperación y rehabilitación integral del centro histórico de la ciudad de Pinar del Río, es imprescindible para el éxito del mismo, dentro del entorno actual y enfrentando la difícil situación económica, arreciada en los momentos actuales.

\section{Bibliografía}

ACOSTA, M. \& HARDOY, J.E., «La urbanización en Cuba Revolucionaria», Política de desarrollo urbano y regional en América Latina, SIAP, Buenos Aires, 1972, pp. 296-309. 
ALCÁZAR, B. DEL \& ALARCÓN, P., «La imagen del producto turístico, objetivo estratégico de marketing». ¿España, un país turísticamente avanzado? I Congreso de Asociación Española de Expertos Científicos en Turismo, Instituto de Estudios Turísticos, Marbella, 1994, pp. 199-217.

ANÓNIMO, «Aroma de tabaco... y algo más», Revista Especial, Editada por el Comité Ejecutivo de la Asamblea Provincial del Poder Popular en Pinar del Río, con motivo de la rendición de cuentas a la Asamblea Nacional en Diciembre de 1984, Impresión Combinado Poligráfico Osvaldo Sánchez, Ciudad de La Habana, 1984.

BENITO, F. «El centro histórico como bien cultural. Una perspectiva desde la ley del patrimonio histórico español» (pp. 9-22). En Primeras Jornadas de Rehabilitación. La intervención en el Centro Histórico. Colegí Oficial d'Arquitectes de Balears, Palma de Mallorca,1993, 134 pp.

BERNAL, B. (coord. A.), «El centro histórico de las ciudades. Patrimonio cultural». las. Jornadas de Geografía Urbana, Edición promocionada por Caja de Burgos, Burgos, 1997.

BERNAL, B. (coord. A.), «Revitalización funcional del Centro Histórico. Un reto de las ciudades históricas. II Jornadas de Geografía Urbana, Universidad de Burgos, Burgos, 1999.

CELI, F.; LABORÍ, M. DE J., «Estructura Urbana de las Ciudades», Instituto de Planificación Física, Ciudad de La Habana. 1988.

DE LA CALLE, M., «La ciudad histórica como destino turístico», Editorial Ariel S. A., Barcelona, 2002. 
